University of Nebraska - Lincoln

DigitalCommons@University of Nebraska - Lincoln

Faculty Publications from the Harold W. Manter Laboratory of Parasitology

10-1992

\title{
Resource Tracking in North American Telorchis spp. (Digenea: Plagiorchiformes: Telorchidae)
}

\author{
Alison Radtke \\ University of Toronto \\ Deborah A. McLennan \\ University of Toronto \\ Daniel R. Brooks \\ University of Toronto,dnlbrooks@gmail.com
}

Follow this and additional works at: https://digitalcommons.unl.edu/parasitologyfacpubs

Part of the Parasitology Commons

Radtke, Alison; McLennan, Deborah A.; and Brooks, Daniel R., "Resource Tracking in North American Telorchis spp. (Digenea: Plagiorchiformes: Telorchidae)" (1992). Faculty Publications from the Harold W. Manter Laboratory of Parasitology. 261.

https://digitalcommons.unl.edu/parasitologyfacpubs/261

This Article is brought to you for free and open access by the Parasitology, Harold W. Manter Laboratory of at DigitalCommons@University of Nebraska - Lincoln. It has been accepted for inclusion in Faculty Publications from the Harold W. Manter Laboratory of Parasitology by an authorized administrator of DigitalCommons@University of Nebraska - Lincoln. 


\title{
RESOURCE TRACKING IN NORTH AMERICAN TELORCHIS SPP. (DIGENEA: PLAGIORCHIFORMES: TELORCHIDAE)
}

\author{
Alison Radtke, Deborah A. McLennan, and Daniel R. Brooks \\ Department of Zoology, Centre for Comparative Biology \& Biodiversity, University of Toronto, Toronto, Ontario, Canada M5S 3G5. e-mail: \\ dbrooks@zoo.utoronto.ca
}

\begin{abstract}
We examine the evolution of host specificity for species of Telorchis, using the methods developed by researchers studying phytophagous insect-plant systems. Optimization of "generalist" compared with "specialist" onto the phylogeny for Telorchis revealed ambiguous patterns, depending on how the 2 terms were defined. Regardless of that definition, most of the evolutionary diversification of this group has been carried out within eucryptodiran turtles, the ancestral host group. From that plesiomorphic background, there appears to have been 2 episodes of specialization by way of a host switch into caudates (ancestor of $T$. stunkardi $+T$. sirenis) and snakes (T. auridistomi), and 1 episode of exuberant expansion producing a true generalist (T. corti). These results, which indicate that most species of Telorchis are tracking widespread plesiomorphic resources, mirror those reported for phytophagous insects and their plants. We believe that establishing a dialogue between the two research groups will be mutually beneficial to both and will strengthen our understanding of the complex factors underlying the evolution of coevolutionary associations.
\end{abstract}

Biologists have been fascinated by the observation that although members of different taxa tend to be associated with one another more than with members of other taxa, those associations are rarely absolute. Sometimes an associate species switches hosts, and a new kind of association begins. This begs the question, when host switching does occur, is it just a random phenomenon (based, for instance, on spatial proximity), or are there more stringent guidelines concerning who is and who is not an acceptable new host? Researchers working with phytophagous insect-plant systems have attempted to answer this question by beginning with the assumption that the insects are tracking a particular resource offered by their plant host(s). If the new host species possesses the same resource as does the colonizer's ancestral host (Jermy, 1984), the new host is simply more of the same habitat (Janzen, 1985). The expansion of the host range may appear to indicate that the associate species is becoming a generalist, when in fact it has not changed its resource preference at all ("faux generalists": Brooks and McLennan, 2002). Second, the associate may speciate on the colonized host species but may still be tracking the plesiomorphic resource. In this case we may be fooled into thinking that a different specialist has evolved when it has not. Such a dynamic produces clades of specialists on the same resource, regardless of whether the ancestral resource is plesiomorphically (e.g., Taber and Pease, 1990; Berenbaum and Passoa, 1999) or convergently (e.g., Becerra, 1997; Köpf et al., 1998) widespread. Finally, an associate species may colonize a host species with a novel resource. If the colonizer already possesses a trait that allows it to access the novel resource (plesiomorphic trait, apomorphic function) it may establish itself on the new species. If the colonizer does not speciate, it has expanded its resource base. In this case, appearances will not be misleading because the colonizing species really has added a novel resource to its list (has become more of a generalist).

Several recent overviews of parasite evolution (Brooks and McLennan, 1993; Poulin, 1998; Trouvé et al., 1998) suggest that host-parasite systems may not differ fundamentally from the insect-plant coevolutionary associations. Parasitologists, however, have traditionally viewed the host species as "being" the resource rather than viewing the host species as "having"

Received 14 January 2002; revised 7 May 2002; accepted 7 May 2002. the resource. Is this distinction likely to make any difference to explanations about the evolution of particular groups of parasites? If, on the one hand, the host species is the resource, then there is a straightforward relationship between host specificity and resource specialization, i.e., the number of host species used by a given parasite indicates its degree of specialization. If, on the other hand, the target resource is a characteristic of the host species (for example, habitat provided by the lungs or the intestine) and not the species itself, the relationship between host specificity and specialization may be complex and historically contingent (Brooks and McLennan, 1993, 2002; Adamson and Caira, 1994; first suggested in a phylogenetic systematic context by Brooks, 1979). In this view, a parasite species showing pronounced host specificity may indicate either cospeciation or peripheral isolates speciation, in which some members of the ancestral population have managed to colonize a host representing a novel (apomorphic) resource, have adapted to that resource, and have speciated as a result (McLennan and Brooks, 1993, 2002; Funk et al., 1995a, 1995b, 1995c; Funk, 1998). The situation is equally complex for parasites inhabiting numerous host species. Such parasite species may be true generalists, that is, they are capable of using a variety of different resources. In other cases the parasite uses the same resource in each host species, so it is actually a resource specialist. It only appears to be a generalist because researchers are recording the number of host species and not the underlying resource that each host is providing.

Researchers working with phytophagous insects and their host plants have amassed a substantial amount of data concerning the dynamics involved in the origin, maintenance, and diversification of coevolutionary associations (e.g., Pellmyr, 1992; Futuyma et al., 1993, 1994, 1995; Bernays and Chapman, 1994; Thompson, 1994; Funk et al., 1995a, 1995b, 1995c; Sperling and Feeny, 1995; Armbruster, 1997; Funk, 1998; Janz and Nylin, 1998; Janz et al., 2001). We believe that it might be useful to apply the techniques used by these researchers to host-parasite systems to ask whether there are any differences between the 2 types of coevolutionary associations. We need 2 things to pursue this investigation: species-level phylogenetic trees for various groups of parasites and a substantial amount of information about preferred hosts for each species being studied. Such information is rare for groups of parasites, but 
the North American species of Telorchis represent a suitable exemplar group.

\section{MATERIALS AND METHODS}

Macdonald and Brooks (1989) provided names and synonyms for 11 North American Telorchis species and a phylogenetic tree with a consistency index of $94 \%$. Subsequently, Friedenfelds et al. (1994) synonymized $T$. auridistomi and $T$. dollfusi, so we have combined host records for both under $T$. auridistomi. Searching the primary literature from 1900 to the present produced the list of vertebrate hosts for each species. The list of the source articles is available on request from D.R.B. Published reports that did not include the species name of the parasite or its host were eliminated from this analysis.

We used an approach designed by researchers studying insect-plant systems (e.g., Janz, 1999; Janz et al., 2001) in which host specificity is investigated using phylogenetic comparisons on different levels of taxonomic resolution for the host groups. So, for example, T. stunkardi inhabits 6 host species, which can in turn be clumped to 2 larger host categories (Caudata and Emydinae). Ancestral conditions were estimated using phylogenetic optimization procedures (Brooks and McLennan, 1991, 2002; Wiley et al., 1991, in press). Possible bias in host specificity associated with uneven sampling was investigated using a simple regression analysis comparing the number of reported hosts with the number of published reports of the parasite. Statistical analyses were performed using Statview 5.0.1, implemented on a MacIntosh G4 computer.

\section{RESULTS}

Regression analysis using all species of North American Telorchis (Fig. 1a) indicated a strong association between the number of reported hosts and the number of published reports of the parasite species. One possible interpretation of this result is that a parasite species might be categorized as a "specialist" because of incomplete knowledge about host range. Closer examination of the data, however, indicated that the analysis was biased because of the inclusion of the extremely "host-rich" $T$. corti. Removing $T$. corti eliminated any significant association (Fig. 1b). Differences in host specificity (as estimated by the number of inhabited host species), therefore, do not appear to be an artifact of incomplete knowledge. ,

Figure 2 depicts the number and the names of the documented host species for each North American Telorchis species. To optimize this information onto the tree, we must categorize each Telorchis species as a generalist or a specialist. If we use the most conservative definition of a specialist (only 1 host used by the parasite species), then the entire Telorchis clade can be categorized as "generalists." A less conservative interpretation, however, considers the specialists to have a low number of host species and the generalists to have a large number of host species. This, of course, is an arbitrary distinction. Clearly $T$. corti is a generalist under any definition. If all other species are categorized as "specialists (1-6 hosts)," then the optimization is simple: being a specialist is plesiomorphic for the clade with 1 transition to the generalist lifestyle. Narrowing the definition of a specialist to include only species with 4 or fewer hosts produces the macroevolutionary pattern depicted in Figure 2. The plesiomorphic state for the clade is still a specialist, but there are now 3 postulated independent transitions to a generalist ( $T$. corti, $T$. stunkardi, and $T$. robustus). If a specialist is defined as a species with 3 or fewer hosts, then the macroevolutionary pattern is reversed; being a generalist is the plesiomorphic condition for the "clade with 4 independent transitions to being a
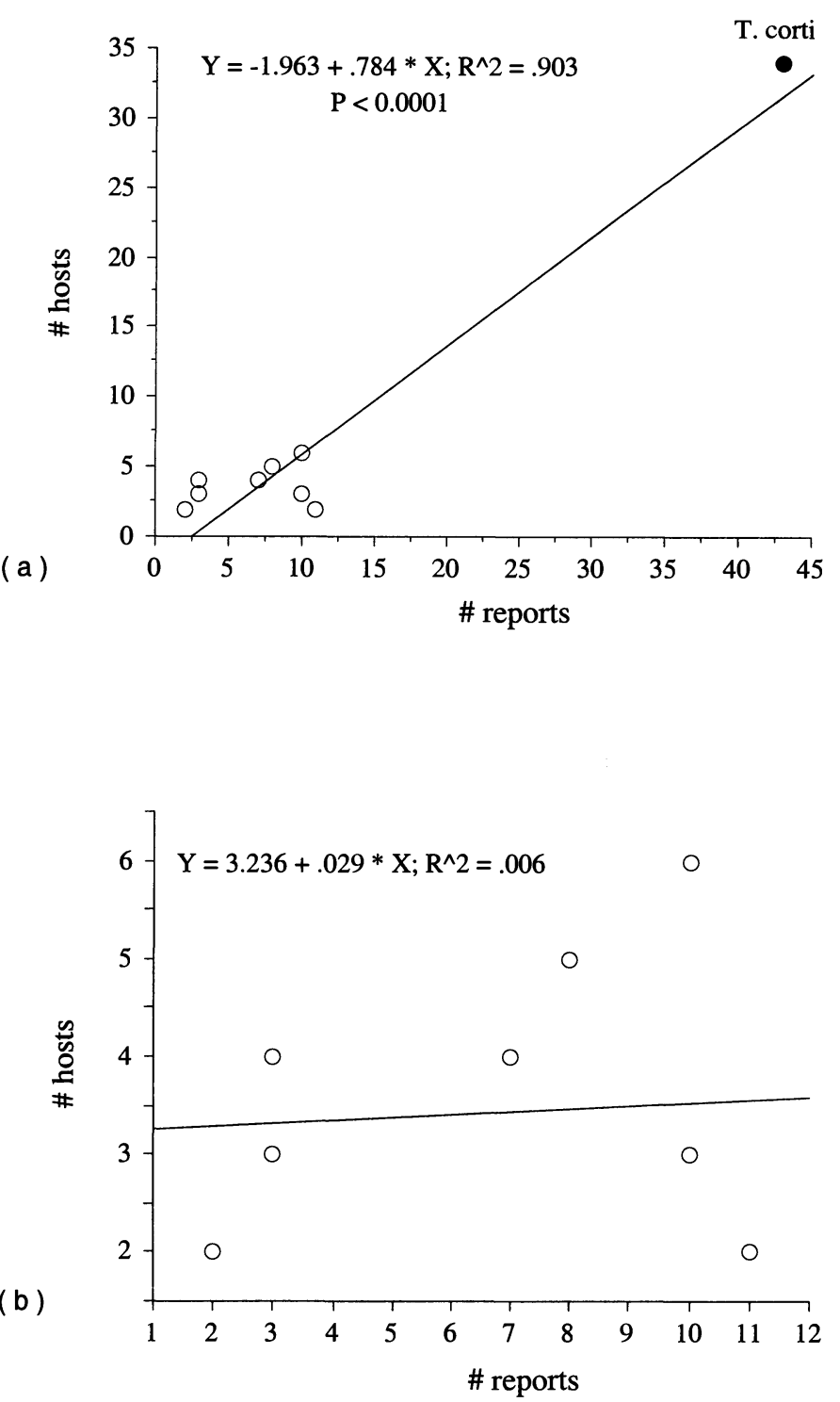

FIGURE 1. Results of regression analysis of number of reported hosts against number of times the parasite species was documented in the literature, including (a) or excluding (b) the extreme generalist $T$. corti.

specialist" (T. sirenis, T. angustus, T. scabrae, and the ancestor of $T$. singularis $+T$. attenuatus).

\section{DISCUSSION}

It was impossible to unambiguously determine whether being a specialist or a generalist was the plesiomorphic condition for the North American Telorchis clade. Depending on how many host species and parasite species were assigned to the designations of a specialist and a generalist, the macroevolutionary patterns indicate a range from "all species are generalists" to "specialist plesiomorphic with 1 transition to generalist." This confusion stems, in part, from the assumption that the host species is the resource being used by the parasite. Researchers working with insect-plant systems have solved this problem, in part, by beginning from the perspective that the host has the resource and then combining host plants into larger monophy- 


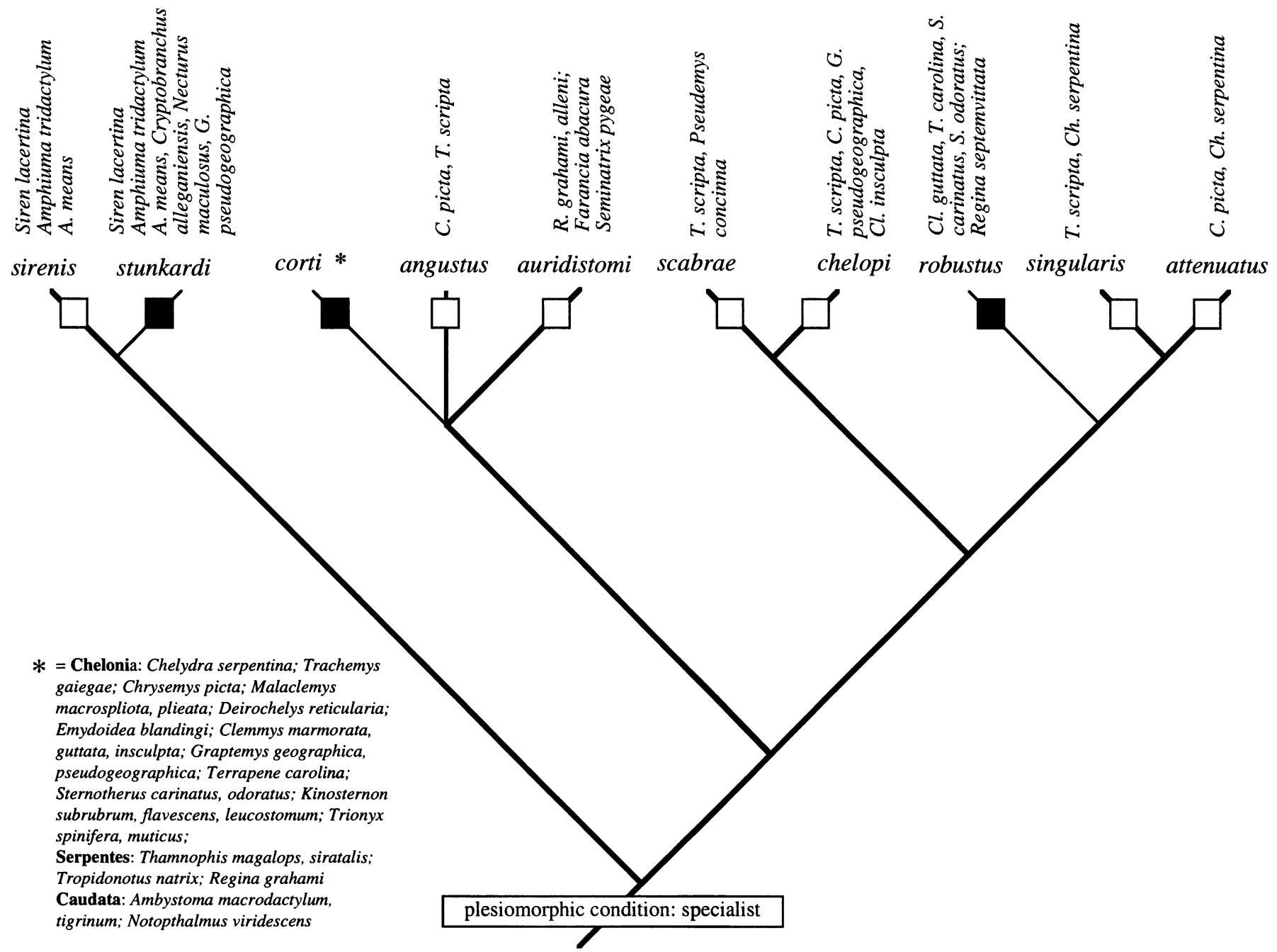

FIGURE 2. Optimizing specialist (open box) compared with generalist (black box) onto the phylogenetic tree for Telorchis (Mcdonald and Brooks, 1989). Specialist, any species with 1-4 hosts. Bold lines, specialist.

letic groupings. Although this kind of analysis initially appears somewhat arbitrary, it is in fact based on the biological assumption that insects are tracking particular resources and that the chemical composition of these resources is identical, or at least highly similar, in closely related plant species. Studies elucidating the actual compounds being tracked by various insect groups support this hypothesis (see e.g., Sperling and Feeny, 1995). Following this protocol we clumped Telorchis hosts into 3 major clades, eucryptodiran turtles (Chelonia: Eucryptodira), caudatan amphibians (Amphibia: Caudata), and colubrid snakes (Serpentes: Colubridae), and optimized these host groups above the phylogenetic tree for the parasites (Fig. 3). For the sake of discussion, we are assuming that turtles are the plesiomorphic hosts for the North American clade. To confirm this hypothesis, we need a robust phylogeny for all members of Telorchis. If that analysis confirms that turtles are the plesiomorphic hosts for the clade, then there have been 2 episodes of specialization by way of a host switch into caudates (ancestor of $T$. stunkardi $+T$. sirenis) and snakes ( $T$. auridistomi), and 1 episode of exuberant expansion producing a true generalist ( $T$. corti).

Regardless of the resolution of the basal host type, our anal- ysis indicates that most of the evolutionary diversification of this group has been carried out within what might be caled "turtle resource space." In addition to the 2 major shifts in host specificity into caudatans and snakes, there has been a substantial amount of host shifting within turtle resource space. That shifting, however, occurs predominantly within the Emydinae (Testudinoidea: black boxes in Fig. 4), with occasional movement either into another testudinoidean (Chelydridae: grey box in Fig. 4) or into a trionychoidean (Trionychidae: white box in Fig. 4), the sister group of the Testudinoidea. Within turtle resource space, then, host switching is at once widespread and yet constrained to Eucryptodirans. Note also that all the new hosts are occupied by $T$. corti. The pattern is similar for Serpentes; all Telorchis species that are associated with snakes are found within colubrids. Host specificity of Telorchis species thus appears to be at the level of major tetrapod groups and not of individual species. In other words, as suggested initially for insect-plant systems (for a close parallel, see Janz et al., 2001), the parasite may be tracking a widespread ancestral resource and not a given host species. What we require now are studies delineating the actual resource that the parasites are tracking. 


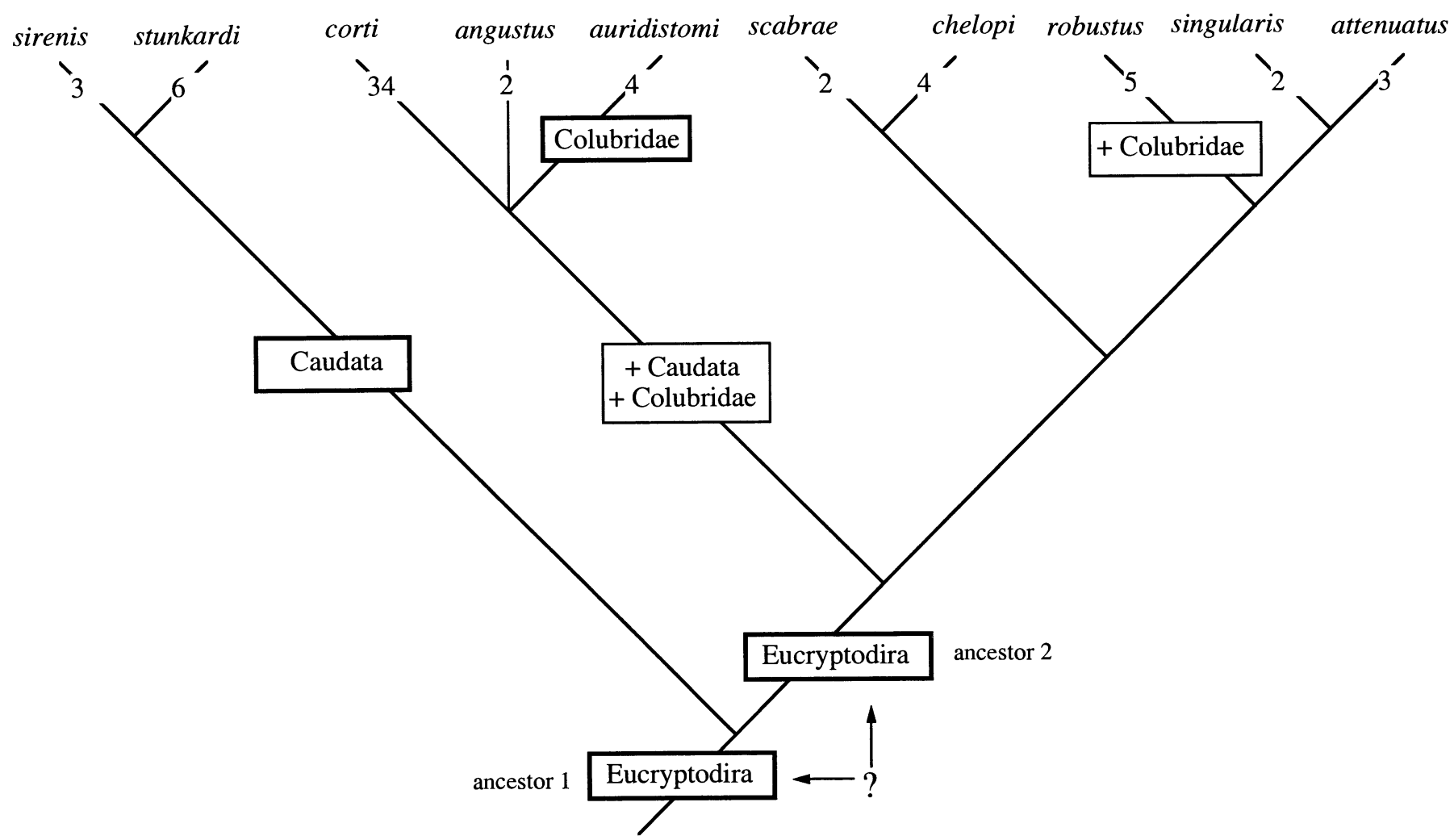

FIGURE 3. Examining the evolution of host specificity by grouping hosts on a higher taxonomic level (Eucryptodira, Colubridae, Caudata). It is difficult to determine the ancestral host type for the clade (it could be either Eucryptodira or Caudata). To resolve this problem, we need to include data from sequential sister-groups to the North American Telorchis group. Bold lines, preference limited to 1 major type of host group.

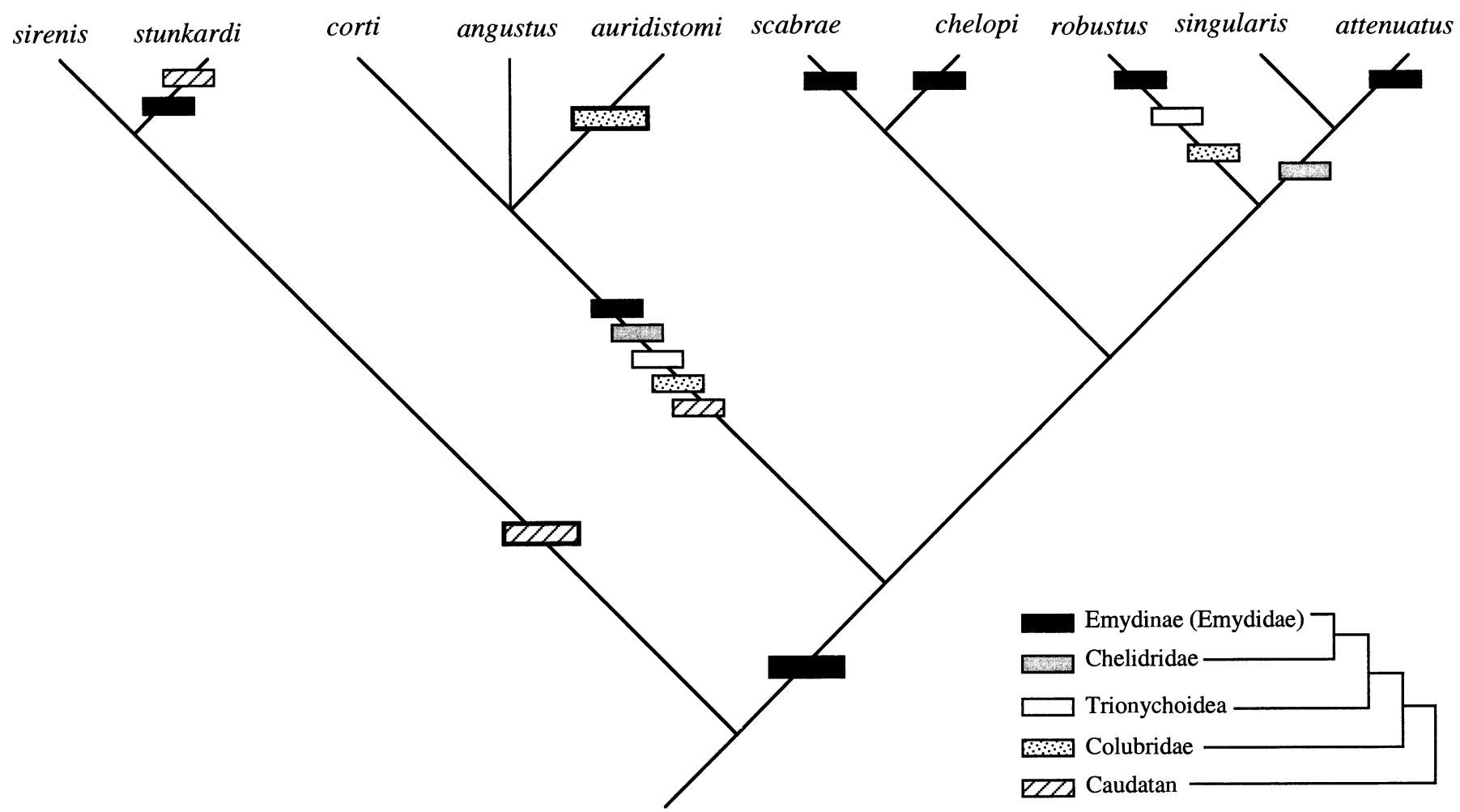

FIGURE 4. Examining the evolution of host specificity by incorporating information about the phylogenetic relationships among host groups (depicted to the right of the phylogenetic tree for the parasites) at a lower taxonomic level. Host switching in these parasites has occurred primarily within the Emydinae and secondarily among their close relatives, the Chelidridae and Trionychoidea, all eucryptodiran turtles. 
For example, if the colonizer is tracking a plesiomorphic resource, both it and its sister species should be able to survive in each other's hosts, just as has been documented for insectplant systems (Futuyma, 1991; Futuyma et al., 1993, 1994, 1995; Funk et al., 1995a, 1995b, 1995c). Studies performed in laboratory settings have demonstrated that at least some parasite species are capable of surviving in many different hosts, including hosts with which they are never associated in nature (Watertor, 1967; Blankespoor, 1974; O'Grady, 1987).

Telorchis corti and its closest relatives are perhaps the most interesting members of this group. By exhibiting the largest number of hosts and the broadest phylogenetic range of hosts by far, $T$. corti differs markedly from its closest relatives, $T$. angustus and T. auridistomi. Unlike $T$. angustus and T. auridistomi, $T$. corti has no autapomorphies, a condition used by some phylogenetic systematists to identify a persistent ancestor (Wiley, 1981; Wiley and Mayden, 1985; Brooks and McLennan, 1991, 1993, 2002). If $T$. corti is the persistent ancestor of $T$. angustus and $T$. auridistomi, it is possible that these changes in host range were associated with the speciation of the latter 2 species. Both species are sympatric with $T$. corti and do not exhibit any obvious differences in preferred location in the host intestine. Telorchis angustus occurs only in hosts also known to be inhabited by $T$. corti and, thus, may be the product of true sympatric speciation, presumably isolated from its sympatric ancestor $T$. corti by an autapomorphic genital pore position (Macdonald and Brooks, 1989). Telorchis auridistomi, on the other hand, occurs in colubrid hosts not known to host $T$. corti, suggesting that $T$. auridistomi may be the result of peripheral speciation, i.e., speciation by colonization. These inferences, of course, are on the basis of the assumption that $T$. corti is indeed 1 widespread species, not a species complex, and that its broad host range was achieved before the evolution of $T$. angustus and $T$. auridistomi, as indicated by phylogenetic optimization (Fig. 2). To pursue this question further, molecular phylogeographic studies of $T$. corti, which has over a dozen synonyms, need to be undertaken. We also need a robust phylogenetic tree for all species of Telorchis to pinpoint the full scope and breadth of host switching, both within and among different host resource types, in this clade.

This study, although preliminary, supports the hypothesis that such different systems as helminth-vertebrate and insect-plant associations may exhibit common macroevolutionary patterns and thus may be subject to, and formed by, common evolutionary dynamics (Brooks and McLennan, 1993, 2002). We believe that the establishment of a dialogue between the 2 research groups will be mutually beneficial to both and may strengthen our understanding of the complex factors underlying the evolution of coevolutionary associations.

\section{ACKNOWLEDGMENTS}

D.A.M and D.R.B acknowledge support for this research through operating grants from the Natural Sciences and Engineering Research Council (NSERC) of Canada.

\section{LITERATURE CITED}

AdAmson, M. L., AND J. N. CAIRA. 1994. Evolutionary factors influencing the nature of parasite specificity. Parasitology 109: S85S95.

ARMBRUSTER, W. S. 1997. Expatiations link evolution of plant-herbivore and plant-pollinator interactions: A phylogenetic inquiry. Ecology 78: $1661-1672$

BECERRA, J. X. 1997. Insects on plants: Macroevolutionary chemical trends in host use. Science 276: $253-256$.

Berenbaum, M. R., and S. Passoa. 1999. Generic phylogeny of North American depressariinae (Lepidoptera: Elachistidae) and hypotheses about coevolution. Annals of the Entomological Society of America 92: 971-986.

BeRnAYS, E., AND M. ChAPMAN. 1994. Host-plant selection by phytophagous insects. Chapman \& Hall, New York, New York, 312 p.

BLANKESPOOR, H. D. 1974. Host-induced variation in Plagiorchis noblei Park, 1936 (Plagiorchiidae; Trematoda). American Midland Naturalist 91: 415-433.

BRooKs, D. R. 1979. Testing the context and extent of host-parasite coevolution. Systematic Zoology 28: 299-307.

- AND D. A. MCLENNAN. 1991. Phylogeny, ecology and behavior: A research program in comparative biology. University of Chicago Press, Chicago, Illinois, 434 p.

- AND $\longrightarrow$ 1993. Parascript: Parasites and the language of evolution. Smithsonian Institution Press, Washington, D.C., 429 p. , AND - 2002. The nature of diversity: An evolutionary voyage of discovery. University of Chicago Press, Chicago, Illinois, $668 \mathrm{p}$.

Friedenfelds, E. V., J. N. CAira, AND B. CAMPBell. 1994. A redescription of Telorchis auridistomi (Digenea: Telorchiidae) with comments on the oral sucker papillae. Journal of the Helminthological Society of Washington 61: 190-199.

FUNK, D. J. 1998. Isolating a role for natural selection in speciation: Host adaptation and sexual isolation in Neochlamisus bebbianae leaf beetles. Evolution 52: 1744-1759.

- D. J. FutuyMA, G. ORTI, AND A. MEYer. 1995a. A history of host associations and evolutionary diversification for Ophraella (Coleoptera: Chrysomelidae): New evidence from mitochondrial DNA. Evolution 49: 1017-1022.

$\longrightarrow, \longrightarrow$, AND $\longrightarrow$. 1995b. Mitochondrial DNA sequences and multiple data sets: A phylogenetic study of phytophagous insects (Chrysomelidae: Ophraella). Molecular Biology and Evolution 12: 627-640.

$-\longrightarrow$, - AND 1995c. A history of host assoevolutionary diversification for Ophraella (Coleoptera: Chrysomelidae): New evidence from mitochondrial DNA. Evolution 49: 1008-1017.

FUTUYMA, D. J. 1991. Evolution of host specificity in herbivorous insects: Genetic, ecological, and phylogenetic aspects. In Plant-animal interactions: Evolutionary ecology in tropical and temperate regions, P. W. Price, T. M. Lewinsohn, G. W. Fernandes, and W. W. Benson (eds.). Wiley, New York, New York, p. 431-454.

, M. C. KeESE, AND S. J. SChefFER. 1993. Genetic constraints and the phylogeny of insect-plant associations: Responses of Ophraella communa (Coleoptera: Chrysomelidae) to host plants of their congeners. Evolution 47: 888-905.

$\longrightarrow,-$, AND D. J. FUNK. 1995. Genetic constraints on macroevolution: The evolution of host affiliation in the leaf-beetle genus Ophraella. Evolution 49: 797-809.

- , J. Walsh, T. Morton, D. J. Funk, and M. C. Keese. 1994 Genetic variation in a phylogenetic context: Responses of two specialized leaf beetles (Coleoptera: Chrysomelidae) to host-plants of their congeners. Journal of Evolutionary Biology 7: 127-146.

JANZ, N. 1999. Ecology and evolution of butterfly host plant range. Jannes Snabbtryck AB, Stockholm, Sweden, 99 p.

$\longrightarrow$, AND S. NYLIN. 1998. Butterflies and plants: A phylogenetic study. Evolution 52: 486-502.

$\longrightarrow$ - - AND K. ВYвOM. 2001. Evolutionary dynamics of host plant specialization: A case study. Evolution 55: 783-796.

JANZEN, D. H. 1985. On ecological fitting. Oikos 45: 308-310.

JERMY, T. 1984. Evolution of insect/host plant relationships. American Naturalist 124: 609-630.

Köpf, A., N. E. Rank, H. Roininen, R. Julkunen-Tiitto, J. M. PasTEELS, AND J. TAHVANAINEN. 1998. The evolution of host-plant use and sequestration in the leaf beetle Phratora (Coleoptera: Chrysomelidae). Evolution 52: 517-528.

MaCDONAld, C. A., AND D. R. BRoOKS. 1989. Revision and phylogenetic analysis of the North American species of Telorchis Luhe, 
1899 (Cercomeria: Trematoda: Digenea: Telorchiidae). Canadian Journal of Zoology 67: 2301-2320.

O'GraDY, R. T. 1987. Phylogenetic systematics and the evolutionary history of some intestinal flatworm parasites (Trematoda: Digenea: Plagiorchioidea) of anurans. Ph.D. Dissertation. University of British Columbia, Vancouver, British Columbia, Canada, 331 p.

Pellmyr, Ø. 1992. The phylogeny of a mutualism: Evolution and coadaptation between Trollius and its seed-parasitic pollinators. Biological Journal of the Linnaean Society 47: 337-365.

Poulin, R. 1998. Evolutionary ecology of parasites. Chapman \& Hall, New York, New York, 212 p.

SPERLING, F. A. H., AND P. FEENY. 1995. Ubmellifer and composite feeding in Papilio: Phylogenetic frameworks and constraints on caterpillars. In Swallowtail butterflies: Their ecology and evolutionary biology, J. M. Scribner, Y. Tsubaki, and R. C. Lederhouse (eds.). Scientific Publishers, Gainesville, Florida, p. 299-306.

Taber, S. W., AND C. M. Pease. 1990. Paramyxovirus phylogeny: Tissue tropism evolves slower than host specificity. Evolution 44: 435-438.
Thompson, J. N. 1994. The coevolutionary process. University of Chicago Press, Chicago, Illinois, $376 \mathrm{p}$.

Trouvé, S., P. Sasal, J. Jourdans, F. N. Renaud, and S. Morand. 1998. The evolution of life history traits in parasitic and free-living platyhelminths: A new perspective. Oecologia 115: $370-378$.

WATERTOR, J. L. 1967. Intraspecific variation of adult Telorchis bonnerensis (Trematoda: Telorchiidae) in amphibian and reptilian hosts. Journal of Parasitology 53: 962-968.

WILEY, E. O. 1981. Phylogenetics: The theory and practice of phylogenetic systematics. Wiley, New York, New York, 439 p.

, AND R. L. MAYDEN. 1985. Species and speciation in phylogenetic systematics, with examples from the North American fish fauna. Annals of the Missouri Botanical Garden 72: 596-635.

, D. J. Siegel-Causey, D. R. Brooks, ANd V. A. Funk. 1991. The complete cladist: A primer of phylogenetic procedures. Special publication no. 19. Museum of Natural History, University of Kansas, Lawrence, Kansas, 158 p.

$\longrightarrow,-, \longrightarrow$, AND $\longrightarrow$. The complete cladist: A primer of phylogenetic procedures. Special publication. Museum of Natural History, University of Kansas, Lawrence, Kansas. [In press.] 